\title{
A New Framework for Entertainment Computing: From Passive to Active Experience
}

\author{
Ryohei Nakatsu', Matthias Rauterberg ${ }^{2}$, and Peter Vorderer ${ }^{3}$ \\ ${ }^{1}$ School of Science and Technology, Kwansei Gakuin University, \\ Kobe-Sanda Campus 2-1, Gakuen, Sanda Hyogo, Japan \\ nakatsulksc.kwansei.ac.jp \\ http://ist.ksc.kwansei.ac.jp/ nakatsu/ \\ 2 Department of Industrial Design, Technical University Eindhoven, \\ Den Dolech 2, 5612AZ Eindhoven, The Netherlands \\ g.w.m.rauterberg@tue.nl \\ http: / / www. idemployee.id.tue.nl/g.w.m.rauterberg/ \\ ${ }^{3}$ Annenberg School for Communication, University of Southern California, \\ 3502 Watt Way, Los Angeles, CA 90089-0281, USA \\ vorderer@usc. edu \\ http: //ascweb.usc.edu/ \\ http://www.ijk.hmt-hannover.de/
}

\begin{abstract}
In this paper a new framework for entertainment computing is introduced and discussed. Based on already existing models and concepts the different links and relationships between enjoyment, flow, presence, and different forms of experiences are shown and their contributions to the new framework reviewed. To address the more fundamental and theoretical issues regarding entertainment, we have to utilize existing theories in information processing, enjoyment and flow theory. Some already possible and probably important conclusions for the design of new entertainment system are drawn.
\end{abstract}

Keywords: Adaptivity, active experience, complexity, enjoyment, entertainment, flow, incongruity, information, integrated presence, learning, play.

\section{Introduction}

The application and research domain of entertainment technology can be separated in different fields: (1) game, (2) sport, (3) novel and movie, and (4) art (see Altman and Nakatsu, 1997). With upcoming developments of advanced technology (Nakatsu, 1998), new media applications can be realized (e.g. Nakatsu, Tosa and Ochi, 1998; Cavazza, 2003). The characteristics of new media are:

$\Delta$ New types of experiences (e.g. Ono, Imai and Nakatsu, 2000)

A [Inter-]active experiences, compared to passive experiences

A Integration of spatial, social, mental and physical presence

Although a variety of theories has been advanced in communication and media psychology that describe and explain specific experiential states commonly understood as 'entertainment' or 'enjoyment', it seems to be very challenging to achieve a 
coherent, integrative view on entertainment. The main reasons for these difficulties are the huge variety of experiences called 'entertainment' (e.g., curiosity, exhilaration, tenderness, pride, melancholy, sexual arousal, perception of being in control or holding power) and the procedural dynamics of entertainment, that is, the strong variability of cognitive and affective dimensions of entertainment over time within the course of media use (Vorderer, Klimmt and Ritterfeld, 2004).

Looking back, various types of considerations on play are already published: Groos (1901/1899), Huizinga (1980/1939), Caillois (1961/1958), Piaget (1969/1947), Csikszentmihalyi (1975), Kauke (1992), Scheuerl (1997), and Raessens and Goldstein (2005). While Groos (1901) argued that children's play is a preparation for life, this was later often credited with the idea that children need to run off their surplus energy. The classification of play by Caillois (1961) is given as follows: (1) Competition (Greek: Agon): Boxing, Soccer, Chess, etc.; (2) Chance (Latin: Alea): Dice, Roulette, etc.; (3) Mimicry (Greek: Mimicry): Actor, Theatrical play, etc.; and (4) Ecstasy (Greek: Ilinx): Swing, Thrill ride, etc. What is missing in Caillois' classification? Ecstatic immersion (Ilinx) is an essential factor in all plays, and Csikszentmihalyi $(1975,1990)$ has noticed this. Caillios confuses physical presence and mental presence. Does it really make sense to classify soccer and chess into the same group? According to the flow concept by Csikszentmihalyi (1990), flow is an essential factor of play in the following sense: (1) flow is same as immersion based on engagement (Douglas and Hargadon, 2000), and (2) the strict border between work and play is eliminated (Rauterberg and Paul, 1990; Rauterberg, 2004a).

\subsection{Curiosity, Arousal and Pleasingness}

Curiosity is defined as a need, 'thirst' or desire for knowledge. The concept of curiosity is central to motivation in relation to mental presence. The term can be used as both a description of a specific behavior as well as a hypothetical construct to explain the same behavior to achieve mental presence. Berlyne (1960) believes that curiosity is a motivational prerequisite for exploratory behavior. Exploratory behavior refers to all activities concerned with gathering information about the environment and/or changing the environment. This leads to the conflict and question of whether exploratory behavior should be defined (1) in terms of the movements that a human performs while exploring, or (2) in terms of the goal or purpose of the observable behavior. A clear distinction between these two seems to be not always possible (Fjeld, Lauche, Bichsel, Voorhorst, Krueger and Rauterberg, 2002).

According to Berlyne (1960) arousal is a function of collative stimulus properties such as complexity, novelty, incongruity (incompatible, discrepant), and surprisingness (unexpected). Environments with medium level of uncertainty (and a positive hedonic tone) produce the most positive aesthetic judgments. Sufficient empirical support exists for Berlyne's curvilinear, inverted U-shape relationship that has been obtained at least for the complexity dimension that determines the arousal level (see Figure 1; based on former work of Wundt, 1874). Similar relationships have been obtained for other dimensions: more novel, more surprising, and less incongruous environments are preferred. Although Berlyne's research was pioneering, he did not sufficiently investigate the relationship to individual skills and preferences. This was addressed by Csikszentmihalyi's research $(1975,1990)$ about 'flow'. 

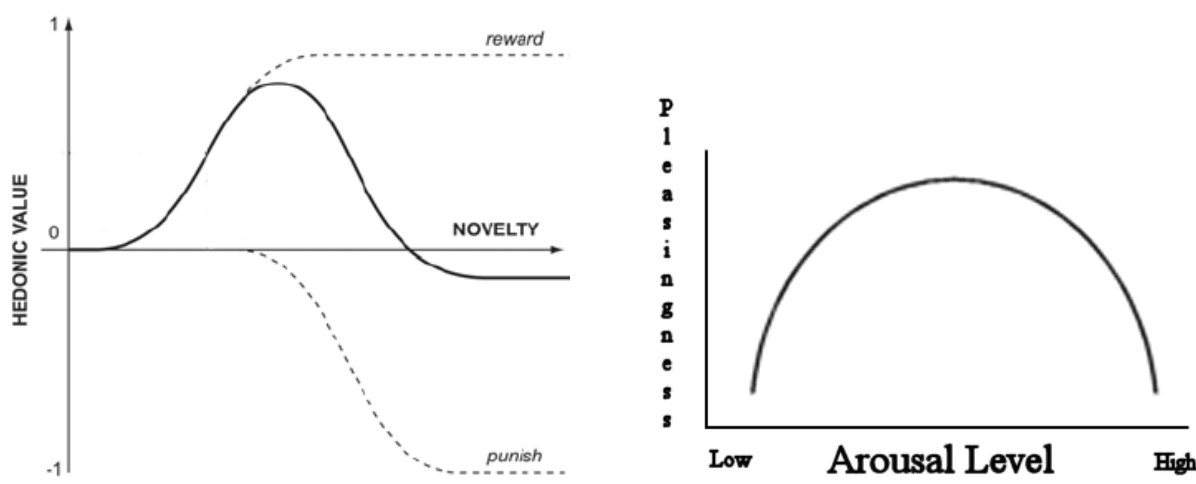

Fig. 1. The Wundt Curve (1874, left) shows the hedonic function used to calculate interest; the hedonic function is shown as a solid line, the reward and punishment sigmoidal curves summed to form the hedonic function are shown dashed. Relationship between cortical arousal level and pleasingness (right, adapted from Berlyne, 1960, p. 201).

\subsection{Conceptual Models of Flow}

All flow component segmentation models are based upon Csikszentmihalyi's definition of flow in terms of skills and challenges (Csikszentmihalyi, 1990, p. 74). However, the segmentation models attempt to account for all possible combinations (components) of high/low skills and challenges. Underlying all of the flow component segmentation models is the central role of skill and challenge as predictors of flow. Novak and Hoffman (1997) compare two flow component segmentation models. The original three component model from Csikszentmihalyi (1990; shown in Figure 2 left) identifies flow as congruent skills and challenges, both high and low; anxiety is identified as the combination of high challenges and low skills, and boredom as high skills and low challenges.
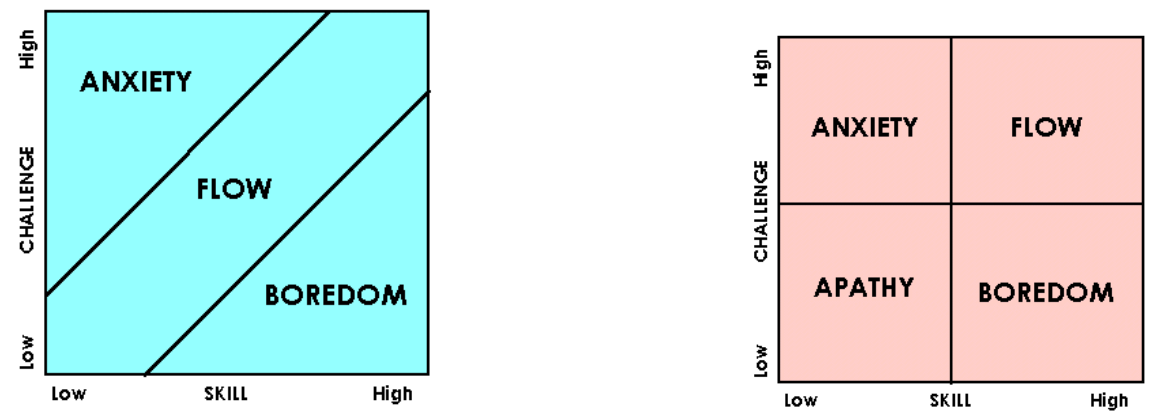

Fig. 2. Three component flow model (left; adapted from Csikszentmihalyi, 1990, p. 74); four component flow model (right; adapted from Novak and Hoffman, 1997) 
In the four component model from Novak and Hoffman (1997; shown in Figure 2 right) identifies flow only in the combination of high skills and high challenges. They separate apathy from flow in the combination of low skills and low challenges. Sufficient empirical support has been found for the reformulated four component model shown in Figure 2 (right). An extension of this four component model is an extended eight component model (Massimini and Massimo, 1988; Ellis, Voelkl and Morris, 1994), which also allows for intermediate (moderate) levels of skills and challenges, and identifies four additional components: arousal, control, relaxation, and worry. As the arousal-relaxation distinction is collinear with challenge, and the control-worry distinction is collinear with skill, the eight component model does not provide any additional information that allows one to predict flow only based upon skill and challenge, over and above the four component model from Novak and Hoffman (1997). All these different multi-component models rely on a non-learning human with an almost fixed level of skills. But humans can and do learn and therefore change their skills and capabilities based on their actions taken.

We are compelled to learn and to make experiences our whole life. Human information processing can not be independent of this life-long learning process. In this sense, humans are open systems. In his law of requisite variety Ashby (1958) pointed out, that for a given state of the environment, an open system has to be able to respond adaptively, otherwise the adaptability and the ability of the system to survive is reduced. A learning system, without input or with constant input, either decays or (in the best case) remains fixed. Learning and the need for variety implies, that with constant input variety from context the requisite variety of the system tends to be not satisfied over time. This is a strong argument against 'one best way' solutions in system design to achieve a sufficient level of enjoyment (Csikszentmihalyi and Hunter, 2003).

\subsection{Information Processing Framework}

Based on the work of Streufert and Streufert (1978), Rauterberg (1995) extended their concepts into a general information processing framework by including learning of adaptive systems. Information and information processing are one of the most important aspects of dynamic systems. The term 'information', that is used in various contexts, might better be replaced with one that incorporates novelty, activity and learning. Hunt (1963) designated the 'arousal potential' of Berlyne (1960) as 'incongruity'. Rauterberg (1995) shifts the semantic and theoretic problems from incongruity to complexity. Incongruity is now defined as the difference in complexity between the learning system (internal complexity of the memory) and the context (external complexity) (see Figure 3).

Humans have a fundamental need for variety: they can't permanently perceive the same context, they can't do always the same things. The fundamental need for variety leads to a different interpretation of human behavior that is often classified as 'exploratory behavior' (Berlyne, 1960) or even 'errors' (Rauterberg and Felix, 1996). Variety is the basis to measure complexity. Rauterberg (1993) could demonstrate a promising approach of measuring behavioral and cognitive complexity in a fully automated way (see also recently Fromm, 2004). We can distinguish two different situations: (1) positive incongruity, and (2) negative incongruity (see Figure 3). If the context complexity of the environment is fixed then the learning process will 
automatically decrease the amount of incongruity, and at the end will turn positive incongruity into negative incongruity. If the actual amount of positive incongruity is below an individual specific threshold then this individual system can either start to actively increase the context complexity or looking for another context with sufficient complexity.

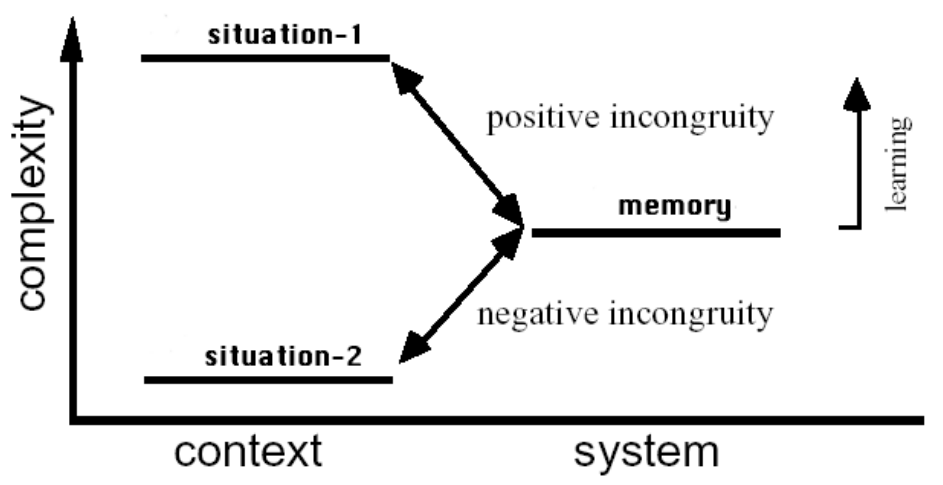

Fig. 3. The difference between the complexity of the system's mental model and the complexity of the situational context is called incongruity (adapted from Rauterberg 1995, p. 59)

Ulich (1987) differentiates between 'boredom' and 'monotony'. Boredom emerges from the feeling of not having enough possibilities to be active (fixed context complexity; see Figure 3). Monotony emerges from the feeling of doing always the same things ('fixed' system complexity; see Figure 3). If the context does not provide sufficient action affordances and opportunities (e.g. context complexity), we are condemned to boredom; if we are not allowed for sufficient variety and learning, we are condemned to monotony, and this monotony effect seems to be independent from the complexity of the system's knowledge structure (memory). Monotony can exists on any level of memory complexity and is mainly caused by insufficient learning and/or action opportunities.

Traditional concepts of information processing are models of homeostasis on a basic level without learning (e.g., Shannon, 1949). Human activity and the irreversible learning process are the main driving forces that cause permanently in-homeostasis in the relationship between a learning system and its context. A suitable model for information processing for learning systems must be conceptualized on a higher level: a homeostatic model of 'in-homeostasis'. The concept to information processing from Rauterberg (1995) includes action and learning and shows an inverted U-shaped function between positive incongruity and strength of particular behavior to keep the positive incongruity level optimized (see Figure 4).

First we have to accept that actual amount of incongruity is individual, context and situation specific; further is this situation specific incongruity permanently drifting based to learning. To keep the incongruity in an optimal range, the learning system has to be provided with a context in which the complexity should permanently increasing as well to provide a sufficient amount of positive incongruity (Csikszentmihalyi and Hunter, 2003). This contextual adaptation rate should be similar or close to the 
individual learning rate ${ }^{1}$. If any of these conditions are not given, then each individual will enter the range of negative emotions and will start actions to re-establish a situation within the range of positive emotions (see Figure 4). If the incongruity increases (e.g., too fast increase of context complexity), the human starts actions to increase confirmation and therefore to decrease external complexity. If the incongruity decreases, the human would react with exploratory or other actions to increase novelty and external complexity.

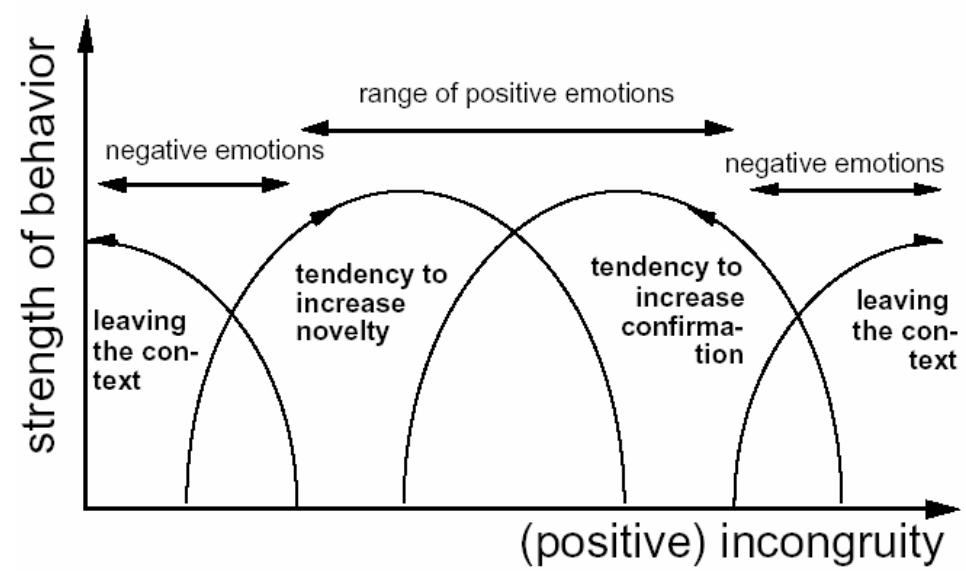

Fig. 4. The coherence between positive incongruity, emotions and strength of observable behavior (taken from Rauterberg 1995, p. 66)

Future research will show how this model will be able to provide important design recommendations for entertainment systems with dynamic and adaptive behavior, beyond game levels with different complexity (see also Fabricatore, Nussbaum and Rosas, 2002). The work of Spronk (2005) looks very promising.

\subsection{Conceptual Model of Flow}

A conceptual model of flow in relation to skill, challenge and presence is described in detail by Hoffman and Novak (1996) and Novak, Hoffman and Yung (2000). Key features of this model are that flow is determined by skills, challenges and presence. Challenges and presence are prerequisites for flow and exploratory behavior. The latest revised version of Hoffman and Novak's structural model is shown in Figure 5. Novak, Hoffman and Yung (2000) indicate the construct of exploratory behavior parallel to flow. Control in Figure 5 refers to Ajzen's (1988) construct of perceived behavioral control, and is indicated as an antecedent, rather than a consequence, of flow. Challenge determines flow directly, and via attention and presence indirectly (see Figure 5). This model of Novak, Hoffman and Yung (2000) is one of the first concepts in which (1) individual skill level (including learning), (2) external challenges, and (3) presence is related to exploratory behavior and flow.

\footnotetext{
${ }^{1}$ This is the central concept and challenge of any kind of didactic (Heiman, 1962).
} 


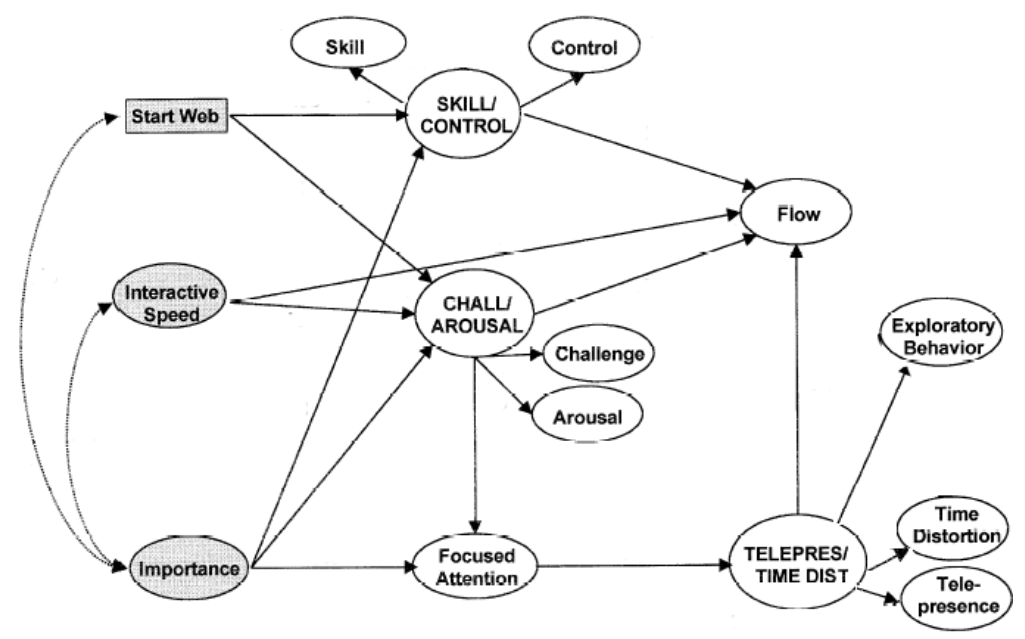

Fig. 5. Structural model of presence and flow in relation to other dimensions (adapted from Hoffman, Novak and Yung, 2000, p. 34)

In the model of Novak, Hoffman and Yung (2000, p. 34; see Figure 5) the direct paths to flow from skill, challenge, and presence are positive and statistically significant. However, there was no support for the hypothesis that greater focused attention corresponds directly to greater flow, although focused attention was found to correspond to greater presence and time distortion. Interactive speed exerts a direct positive influence on flow, but greater speed did not correspond to greater focused attention or presence and time distortion. Greater importance was positively associated with greater focused attention, and the longer the usage was, the greater the users' skill and control in the virtual environment.

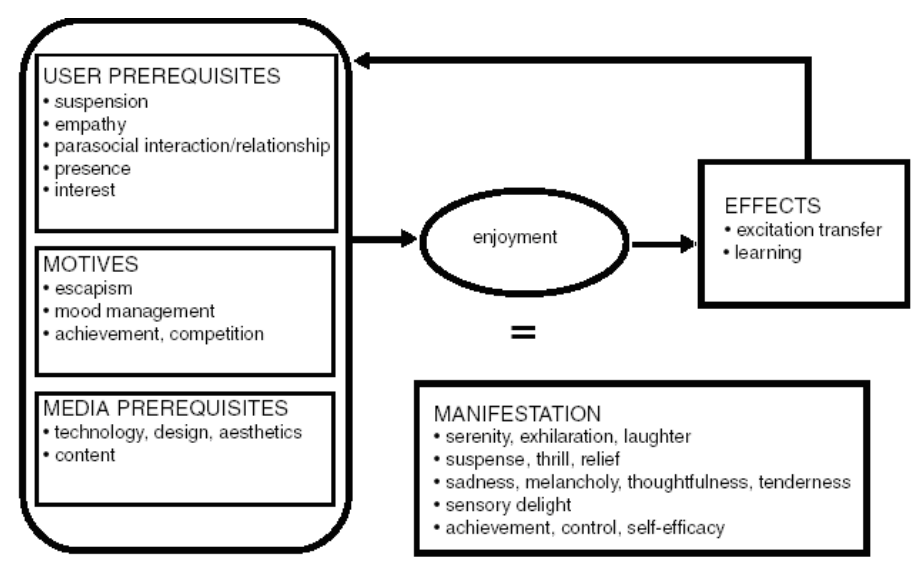

Fig. 6. Enjoyment as the central concept for entertainment experience (adapted from Vorderer, Klimmt and Ritterfeld, 2004, p. 393) 
Additionally Vorderer, Klimmt and Ritterfeld (2004) propose an integrated view of media entertainment that is capable of covering more of the dimensional complexity and dynamics of entertainment experiences than existing theories can do. Based on a description of what is meant by complexity and dynamics, the authors outline a conceptual model that is centered around enjoyment as the core of entertainment, and that addresses prerequisites of enjoyment which have to be met by the individual user and by the given media product. The theoretical foundation is used to explain why people display strong preferences for being entertained (motivational perspective; see Vorderer and Bryant, 2005) and what kind of consequences entertaining media consumption may have (effects perspective, e.g., facilitation of learning processes; Figure 6).

\section{A New Framework for Entertainment Computing}

Human activities in the context of entertainment experiences can be related to two major classes:

A Passive Experiences: Reading novels, watching movies; people watch experiences of others, etc.; sometimes called 'lean back' entertainment.

A Active Experiences: Doing sports, creating art; people are active participants in the dynamic situation (e.g. Nakatsu, Tosa and Ochi, 1998) ; sometimes called 'lean forward' entertainment.

Passive and active experiences are the two poles of the 'activity' dimension. Active experience is mainly correlated with 'physical' presence, and passive experience mainly with 'mental' presence. Nakatsu (2004) combines 'physical' and 'mental' presence into 'integrated' presence.

A Physical Presence: hear sound, look at image, utter speech, move body, exercise, etc.

- Mental Presence: use language, read a book, listen to music, watch picture or movie, etc.

A Integrated Presence: Karaoke, theatrical play, musical performance, sculpture, professional sport, etc.

Integrated presence is based on a proper combination of a certain amount of physical activity and mental imaginations. Mind and body come together in a more enjoyable form of experiences and presence than each separately could achieve. Nakatsu (2004) proposed a new classification of entertainment applications in which the dimension of 'passive versus active experience' is related to the dimension of presence which is separated into 'physical', 'mental' and 'integrated' forms. In this new framework all existing and upcoming entertainment applications can be classified and categorized in a comprehensive new way (see Figure 7).

Virtual environments and new entertainment have added even more challenges to entertainment theory. Clearly, the amount and state of presence that virtual environments can elicit is closely connected to new entertainment (Klimmt and Vorderer, 2003). However, since presence itself is a multi-dimensional concept, a very large number of connections between (dimensions and precursors of) presence and (dimensions / manifestations of) entertainment is conceivable. For example, interactivity, which is a key element of virtual environments and an important determinant of inte- 
grated presence, holds fundamental implications for the quality and intensity of new entertainment, primarily for individuals who can cope with the additional learning challenges of interactive media (Vorderer, Knobloch and Schramm, 2001).

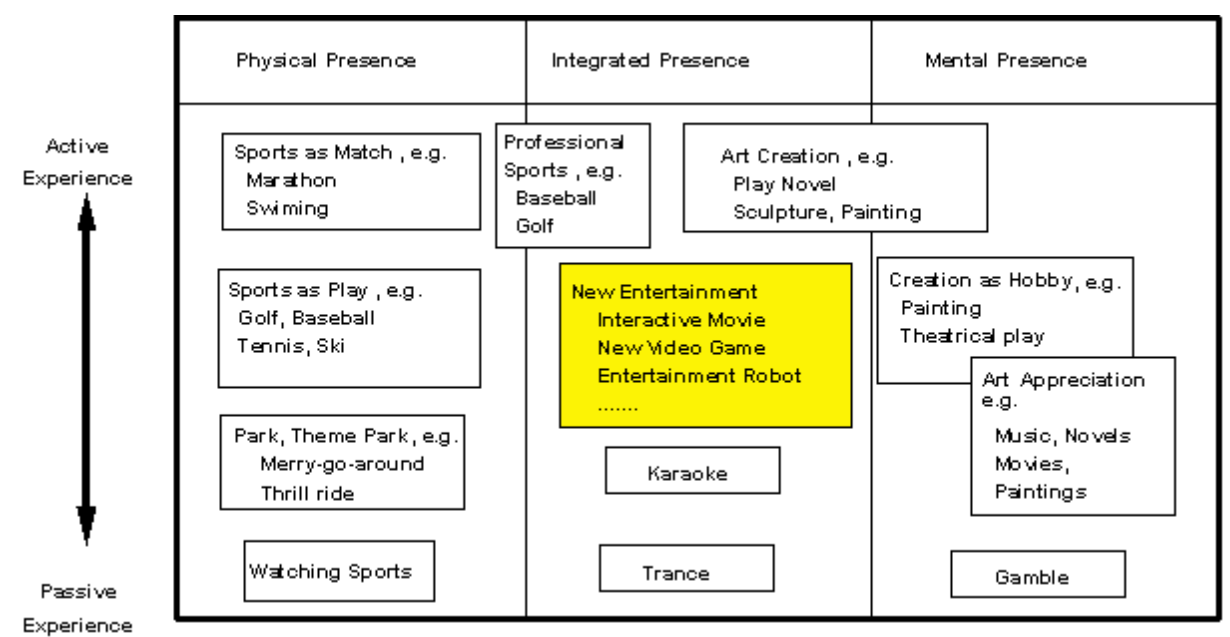

Fig. 7. Classification framework for entertainment applications (adapted from Nakatsu, 2004)

Klimmt (2003) and Klimmt and Hartmann (2005) has linked interactivity to such diverse dimensions of enjoyment as effectance, suspense, curiosity, pride, and simulated experience of attractive action roles. Vorderer, Hartmann and Klimmt (2003) have discussed the implications of interactivity for competitive forms of entertainment. On the other side based on an intensive literature search (Rauterberg, 2004b), Rauterberg could find that collaborative forms of entertainment have significant positive effects on human growth and development. Other key characteristics such as sensuous richness (Turner, Turner and Caroll, 2005), audio-visual realism (Shirabe and Baba, 1997), digital narratives (Cavazza, 2003), aesthetics (Overbeeke and Wensveen, 2004; Wensveen and Overbeeke, 2004), and intercultural differences (Rauterberg, 2004a) have not yet been systematically connected to entertainment theory.

Another important link between presence and new entertainment refers to the assumption that enjoyment only occurs in situations when users perceive themselves as being in control (Früh and Stiehler, 2003). However, very immersive new entertainment applications could induce very captive and overwhelming feelings of presence, which in turn might lead to a reduction of perceived control and thus diminish enjoyment. From this perspective, entertainment experiences can only unfold if users achieve a balance between inner distance to and 'being captivated' by a virtual environment, which preserves a required minimum of perceived control over the situation (Kiili, 2005). The relationship between 'overwhelming' presence, perceived control and entertainment is thus another key objective of future theoretical and empirical investigations. 


\section{Conclusions}

In this paper we have several theoretical concepts presented and discussed which can contribute to a new framework for entertainment computing. One major optimization criteria for the design of future entertainment applications (e.g. interactive movie, new type of video games, entertainment robots, etc) is enjoyment (Tosa and Nakatsu, 1998; Vorderer, Klimmt and Ritterfeld, 2004). To reach enjoyment integrated presence has to be combined with active experience. Active experience is mainly based on sufficient motor behavior involved in user actions: the cognitively and emotionally enhanced body! If the user is in a flow state, then active experience can lead to integrated presence. One of the remaining questions is how to get the user into the flow? Let us assume, we have a sufficient interactive environment which involves physical and mental presence (to achieve integrated presence), how should we link the challenges from this action space to the actual skill level of the user? One possible and promising answer is a sufficient adaptive system behavior to the user's learning progress. Enabling the user to keep his or her optimal incongruity (= proper match of challenges to skills), is probably the best design to reach enjoyable integrated presence.

\section{References}

Ajzen, I. (1988). Attitudes, Personality, and Behavior. Chicago: Dorsey Press.

Altman, E. \& Nakatsu, R. (1997). Interactive Movies: Techniques, Technology and Content. Course Notes, No. 16, ACM SIGGRAPH'97.

Ashby, R.W. (1958). Requisite variety and its implications for the control of complex systems. Cybernetica, Vol. 1, No. 2, pp. 83-99.

Berlyne, D.E. (1960). Conflict, Arousal, and Curiosity. New York: McGraw Hill.

Caillois, R. (1961). Man, Play and Games [Translated from 1958]. New York: Free Press.

Cavazza, M. (2003).Virtual Unreality: Storytelling in Virtual Environments. In: Proceedings of the ACM Symposium on Virtual Reality Software and Technology VRST'03 (pp. 4-5), New York: ACM.

Csikszentmihalyi, M. \& Hunter, J. (2003). Happiness in everyday life: the uses of experience samples. Journal of Happiness Studies, Vol 4, pp. 185-199.

Csikszentmihalyi, M. (1975). Beyond boredom and anxiety: experiencing flow in work and play. San Francisco: Jossey-Bass Publishers.

Csikszentmihalyi, M. (1990). Flow: the psychology of optimal experience, New York: Harper Perennial.

Douglas, Y. \& Hargadon, A. (2000). The pleasure principle: immersion, engagement, flow. In: Proceedings of ACM Conference on Hypertext'O0 (pp. 153-160), New York: ACM.

Ellis, G.D., Voelkl, J.E. \& Morris, C. (1994). Measurement and analysis issues with explanation of variance in daily experience using the flow model. Journal of Leisure Research, Vol. 26, No. 4, pp. 337-356.

Fabricatore, C., Nussbaum, M. \& Rosas, R. (2002). Playability in action videogames: a qualitative design model. Human-Computer Interaction, Vol. 17, pp. 311-368.

Fjeld M., Lauche, K., Bichsel, M., Voorhorst, F., Krueger, H. \& Rauterberg, M. (2002). Physical and virtual tools: activity theory applied to the design of groupware. Computer Supported Cooperative Work, Vol. 11, Nos. 1-2, pp. 153-180.

Fromm, J. (2004). The emergence of complexity. Kassel: Kassel University Press. 
Früh, W. \& Stiehler, H.-J. (2003; Eds.). Theorie der Unterhaltung-ein interdisziplinärer Diskurs [Translated: Entertainment theory-an interdisciplinary discourse]. Köln: van Halem Verlag.

Groos, K. (1901). The play of man [Translated from 1899]. New York: D. Appleton.

Heimann, P. (1962). Didaktik als Theorie und Lehre. Die deutsche Schule, Vol. 54, No. 9, pp. 407-27.

Hoffman, D.L. \& Novak, T.P. (1996). Marketing in hypermedia computer-mediated environments: conceptual foundations. Journal of Marketing, Vol. 60, pp. 50-68.

Huizinga, J. (1980) (translated from 1939). Homo Ludens: a study of the play element in culture. London: Routledge and Kegan Paul.

Hunt, J.M.V. (1963). Motivation inherent in information processing and action. In: O.J. Harvey (Ed.) Motivation and social interaction: the cognitive determinants (pp. 35-94). New York: Ronald Press.

Kauke, M. (1992). Spielintelligenz: spielend lernen-spielend lehren? [Translation: Play intelligence: playful learning-playful teaching]. Heidelberg: Spektrum Press.

Kiili, K. (2005). Digital game-based learning: towards an experimental gaming model. Internet and Higher Educations, Vol. 8, pp. 13-24.

Klimmt, C. \& Hartmann, T. (2005, in press). Effectance, self-efficacy, and the motivation to play computer games. In P. Vorderer \& J. Bryant (Eds.), Playing video games: Motives, responses, and consequences. Mahwah: Lawrence Erlbaum Associates.

Klimmt, C. \& Vorderer, P. (2003). Media Psychology 'is not yet there': introducing theories on media entertainment to the Presence debate. Presence: Teleoperators and Virtual Environments, 12 (4), 346-359.

Klimmt, C. (2003). Dimensions and determinants of the enjoyment of playing digital games:A three-level model. In M. Copier \& J. Raessens (Eds.), Level Up: Digital Games Research Conference (pp. 246-257), Utrecht: Utrecht University.

Massimini, F. \& Massimo, C. (1988). The systematic assessment of flow in daily experience. In M. Csikszentmihalyi and I. Csikszentmihalyi (Eds.), Optimal Experience: Psychological Studies of Flow in Consciousness, (pp. 288-306), New York: Cambridge University Press.

Nakatsu, R., Tosa, N. \& Ochi, T. (1998). Interactive movie system with multi-person participation and anytime interaction capabilities. In: Proceedings of the 6th ACM International conference on Multimedia: Technologies for interactive movies (pp. 2-10), New York: ACM.

Nakatsu, R. (1998). Nonverbal information recognition and its application to communication. In: Proceedings of the 6th ACM International Conference on Multimedia: Face/gesture recognition and their applications (pp. 2-9), New York: ACM.

Nakatsu, R. (2004). Entertainment computing. Retrieved March 2005 from: http://www.idemployee.id.tue.nl/g.w.m.rauterberg/presentations/Nakatsu(2004)/Nakatsu\%5 B2004\%5D_files/frame.htm

Novak, T.L., Hoffman, D.P. \& Yung, Y.F. (2000). Measuring the customer experience in online environments: a structural modeling approach. Marketing Science, Vol. 19, No. 1, pp. 22-42.

Novak, T.P. \& Hoffman, D.L. (1997). Measuring the flow experience among web users. Retrieved from http://elab.vanderbilt.edu/research/papers/pdf/manuscripts/FlowMeasuringFlowExpJul1997-pdf.pdf

Ono, T., Imai, M. \& Nakatsu, R. (2000). Reading a robot's mind: a model of utterance understanding based on the theory of mind mechanism. Advanced Robotics, Vol. 14, No. 4, pp. 311-326.

Overbeeke, C.J. \& Wensveen, S.A.G. (2004). Beauty in use. Human-Computer Interaction, Vol. 19, No. 4, pp. 367-369.

Piaget, J. (1962). Play, dreams and imitation in childhood [Translated from 1947]. New York: Norton.

Raessens, J. \& Goldstein, J. (2005, Eds.). Handbook of Computer Game Studies. Cambridge: MIT Press. 
Rauterberg, M. \& Felix, D. (1996). Human errors: disadvantages and advantages. In: Proceedings of 4th Pan Pacific Conference on Occupational Ergonomics PPCOE'96 (pp. 25-28). Hsinchu: Ergonomics Society Taiwan.

Rauterberg, M. \& Paul, H.-J. (1990). Computerspiele - Computerarbeit: Spielerische Momente in der Arbeit. In: F. Nake (Ed.), Ergebnisse der 9. Arbeitstagung "Mensch-Maschine-Kommunikation" (Informatics Report No. 8/90, pp. 13-49). Bremen: University Bremen.

Rauterberg, M. (1993) AMME: an automatic mental model evaluation to analyze user behaviour traced in a finite, discrete state space. Ergonomics, Vol. 36, No. 11, pp. 13691380.

Rauterberg, M. (1995). About a framework for information and information processing of learning systems. In: E. Falkenberg, W. Hesse \& A. Olive (Eds.), Information System Concepts--Towards a consolidation of views (pp. 54-69). London: Chapman \& Hall.

Rauterberg, M. (2004a). Enjoyment and Entertainment in East and West. In: M. Rauterberg (ed.), Entertainment Computing ICEC'04 (pp. 176-181). Lecture Notes in Computer Science, Vol. 3166, Springer Press.

Rauterberg, M. (2004b). Positive effects of entertainment technology on human behaviour. In: R. Jacquart (ed.), Building the Information Society (pp. 51-58). IFIP, Kluwer Press.

Scheuerl, H. (1997, 12th edition, Ed.): Theorien des Spiels [Translation: Theories of Play]. Weinheim: Beltz.

Shannon, C.E. (1949). The mathematical theory of communication. In: C.E. Shannon \& W. Weaver (Eds.) The mathematical theory of communication (pp. 29-125). University of Illinois Press.

Shirabe, M. \& Baba, Y. (1997). Do three-dimensional real-time interfaces really play important roles?. In: M.J. Smith, G. Salvendy \& R. Koubek (Eds.) Design of computing systems: social and ergonomic considerations (pp. 849-852), Amsterdam: Elsevier.

Spronk, P. (2005). Adaptive Game AI. PhD Thesis, University of Maastricht, Netherlands

Streufert, S. \& Streufert, S.C. (1978). Behavior in the complex environment. Washington: Winston \& Sons.

Tosa, N. \& Nakatsu, R. (1998). Interactie poem system. In: Proceedings of $6^{\text {th }}$ ACM International Conference on Multimedia (pp. 115-118), New York: ACM.

Turner, P., Turner, S. \& Carroll, F. (2005) The Tourist Gaze: Towards Contextualised Virtual Environments. In: P. Turner \& E. Davenport (Eds.) Spaces, Spatiality and Technology. (The Kluwer International Series on Computer Supported Cooperative Work, Vol. 5), Springer.

Ulich, E. (1987). Umgang mit Monotonie und Komplexität [Translation: Dealing with monotony and complexity]. Technische Rundschau, Vol. 5, pp. 8-13.

Vorderer, P. \& Bryant, J. (2005, in press, Eds.). Playing video games: Motives, responses, consequences. Mahwah, NJ: Lawrence Erlbaum Associates.

Vorderer, P., Hartmann, T. \& Klimmt, C. (2003). Explaining the enjoyment of playing video games: the role of competition. In: Proceedings of the $2^{\text {nd }}$ IFIP International Conference on Entertainment Computing ICEC'03 (online). New York: ACM.

Vorderer, P., Klimmt, C. \& Ritterfeld, U. (2004). Enjoyment: At the heart of media entertainment. Communication Theory, Vol. 14, No. 4, pp. 388-408.

Vorderer, P., Knobloch, S. \& Schramm, H. (2001). Does entertainment suffer from interactivity? The impact of watching an interactive TV movie on viewers' experience of entertainment. Media Psychology, Vol. 3, No. 4, pp. 343-363.

Wensveen, S.A.G. \& Overbeeke, C.J. (2004). The role of balance and symmetry in the expression of valence, arousal and urgency in interaction design. Bulletin of Psychology and the Arts, Vol. 4, No. 2, pp. 77-80.

Wundt, W. (1874). Grundzüge der physiologischen Psychologie [Translation: Principles of physiological psychology]. Leipzig: Engelmann. 